\title{
KETERLIBATAN ORANGTUA DALAM PENANGANAN ANAK BERKEBUTUHAN KHUSUS
}

\author{
${ }^{(1)}$ Khairunisa Rani, ${ }^{(2)}$ Ana Rafikayati dan ${ }^{(3)}$ Muhammad Nurrohman Jauhari \\ ${ }^{(1)}$ Mahasiswa, ${ }^{(2,3)}$ Dosen Pogram Studi Pendidikan Khusus FKIP Universitas PGRI Adi Buana Surabaya \\ Email: khoirun.nisa313354@gmail.com ${ }^{1}$ ana@unipasby.ac.id ${ }^{2}, \underline{\text { Muhammadnurrohmajuhari@gmail.com }}{ }^{3}$
}

\begin{abstract}
ABSTRAK
Agar berhasil dalam intervensi dini dan mengingat anak pada usia yang masih muda, tentu peran orang tua sangatlah penting. Ini karena orang tua adalah anak terdekat dan orang yang selalu bersama anak. Keterlibatan orang tua sangat penting untuk mewujudkan pembelajaran yang optimal di masa keemasan anak-anak. Hal ini diperkuat oleh pendapat Wu dan Brown yang menyatakan bahwa partisipasi orang tua merupakan salah satu faktor penting yang menentukan perkembangan anak-anak dengan kebutuhan khusus. Namun, dalam prakteknya banyak orang tua masih kurang memahami anak-anak mereka. Banyak orangtua mengalami kesulitan membesarkan anak-anak mereka. Orangtua tidak tahu apa yang bisa mereka lakukan untuk mengoptimalkan perkembangan anak mereka. Mengingat topik anak berkebutuhan khusus juga sangat terbatas dibicarakan secara umum, para orang tua, ini semakin sulit bagi orang tua untuk mendapatkan informasi tentang bagaimana menangani anak-anak mereka. Berdasarkan masalah ini, orang tua dari anak-anak dengan kebutuhan khusus perlu dilatih untuk dapat mendidik anak-anak mereka dengan benar dan anak-anak dapat berkembang secara optimal.
\end{abstract}

Kata kunci: Orangtua Anak dengan Kebutuhan Khusus, Pendidikan, Keterlibatan

\section{ABSTRACT}

To succeed in early intervention and remember the age of young children, of course the role of parents is important. This is because the parent is the closest child and the person who is always with the child. Parental involvement is very important to realize optimal learning in the golden age of children.It's strengthened by the opinion of $W u$ and Brown that states that parent participation is one important factor that determines the development of children with special needs. However, in practice many parents still lack understanding of their children. Many parents have difficulty raising their children. Parents do not know what they can do to optimize their child's development. Given the topic of children with special needs is also very limited discussed in general, parents, it is increasingly difficult for parents to get information about how to deal with their children. Based on these problems, the parents of children with special needs need trained to able educate their children properly and children can develop optimally.

Keyword: Parents Children with Special Needs, Education, Involvement

\section{PENDAHULUAN}

Isu diskriminasi terhadap pendidikan Anak Berkebutuhan Khusus (ABK) telah lama bergulir di Indonesia. Selama ini pendidikan yang tersedia bagi mereka hanya terbatas di setting pendidikan segregasi (eksklusif). Terdapat 3 layanan segregasi yang diselenggarakan oleh pendidikan Indonesia yaitu, (1) sekolah khusus yang hanya melayani peserta didik dengan jenis kelainan yang sama, (seperti: SLB/A, SLB/B, SLB/C dst), (2) sekolah khusus yang menampung berbagai jenis kelainan, (seperti: SDLB, SMPLB dan SMALB), dan (3) sekolah terpadu yakni sekolah reguler (nonSLB) yang menerima peserta didik berkebutuhan khusus.

Dari ketiga setting layanan pendidikan tersebut, layanan dimana anak berkebutuhan khusus dapat belajar bersama dengan siswa regular (non-ABK) adalah sekolah terpadu. Meskipun begitu, pada settingpendidikan ini, peserta didik khusus yang harus menyesuaikan dengan sistem 
sekolah baik kurikulum, guru, sarana prasarana pembelajaran, dan kegiatan belajar mengajar. Oleh karena itu banyak siswa berkebutuhan khusus yang gagal dalam belajar di sekolah regular misalnya tidak naik kelas, tidak lulus Ujian Nasional atau bahkan dikeluarkan karena tertinggal.

Berdasarkan isu-isu dunia tentang pendidikan untuk semua, selanjutnya di Indonesia mulai dikembangkan sistem pendidikan inklusif, sebuah sistem pendidikan yang ditengarai lebih ramah dan tidak diskriminatif terhadap mereka. Pendidikan inklusif adalah sistem penyelenggaraan pendidikan yang memberikan kesempatan kepada semua peserta didik yang memiliki kelainan dan memiliki potensi kecerdasan dan/atau bakat istimewa untuk mengikuti pendidikan atau pembelajaran dalam lingkungan pendidikan di sekolah reguler bersama-sama dengan peserta didik regular, mulai dari jenjang pendidikan usia dini (PAUD) hingga jenjang SMA atau SMK.

Lembaga Pendidikan Anak Usia Dini adalah suatu lembaga yang memberikan layanan pengasuhan, pendidikan dan pengembangan bagi anak lahir sampai enam tahun dan atau samapai dengan delapan tahun. Dengan maraknya isu pendidikan inklusif, sekarang ini mulai dikembangkan PAUD inklusif. Hal ini dilakukan mengingat pentingnya identifikasi dan intervensi dini bagi Anak Berkebutuhan Khusus (ABK).

Untuk mensukseskan intervensi dini dan mengingat usia anak yang masih kecil, tentu peran orang tua adalah yang terpenting. Hal ini dikarenakan orangtua adalah orang terdekat anak dan orang yang selalu bersama anak. Keterlibatan orangtua adalah sangat penting untuk mewujudkan pembelajaran yang optimal dimasa usia emas anak.Hal ini dikuatkan oleh pendapat Wu dan Brown yang menyatakan bahwa partisipasi orangtua adalah salah satu faktor penting yang menentukan perkembangan anak berkebutuhan khusus.

$$
\text { Meskipun begitu, dalam }
$$
pelaksanaannya banyak orangtua yang masih kurang memahami anak mereka. Banyak orangtua yang mengalami kesulitan dalam membesarkan anak mereka. Orang tua kurang tahu apa yang bisa dilakukan untuk mengoptimalkan perkembangan anak. Mengingat topik tentang anak berkebutuhan khusus juga sangat terbatas diperbincangkan secara umum,

Berdasarkan wawancara kepada Kepala Dinas Pendidikan Cabang Sumenep pada 20 Februari 2018, diperoleh data bahwasanya di Kabupaten Sumenep baru sedikit orang tua anak berkebutuhan khusus yang terlibat terhadap pendidikan anak mereka. Padahal keterlibatan orangtua terhadap pendidikan sangat penting. selain menyerahkan anak ke pihak sekolah, orangtua juga perlu diajarkan cara menangani anak mereka dirumah untuk membantu perkembangan anak secara optimal. Untuk dapat memiliki kompetensi tersebut, perlu dilakukan pembelajaran atau pelatihan kepada orangtua. Pelaksanaan pendidikan dengan memberdayakan orang tua merupakan salah satu guna mengoptimalkan perkembangan anak.

Berdasarkan permasalahan tersebut, maka tim pelaksana melakukan pengabdian kepada masyarakat tentang keterlibatan orangtua dalam penanganan anak berkebutuhan khusus kepada orangtua anak berkebutuhan khusus di KabupatenSumenep. diharapkan dengan adanya pengabdian kepada masyarakat berupa workshop tentang keterlibatan orangtua terhadap penanganan anak berkebutuhan khusus ini, orangtua dapat menambah wawasan mereka sehingga orangtua dapat menangani anak mereka dengan tepat dan anak dapat berkembang secara optimal.

\section{METODE PELAKSANAAN}

Kegiatan Pengabdian Kepada Masyarakat di PK-PLK Cinta Ananda Kabupaten Sumenep dilaksanakan dengan memberikan materi tentang:

1. Peran orang tua dalam pendidikan anak berkebutuhan khusus, dijelaskan apakah orang tua memiliki peran penting terhadap perndidikan anak berkebutuhan khusus, atau hanya semata tanggung jawab guru di sekolah. 
2. Keterlibatan Orang Tua dalam Kegiatan Pemberian Layanan Pendidikan Bagi Anak Berkebutuhan Khusus. Dijelaskan bahwa orang tua merupakan agen pertama dalam pemberian pendidikan bagi anak berkebutuhan khusus. Guru hanya sebagai pelengkap saja, bukan jadi yang utama.

Pemberian materi tersebut disampaikan oleh Ana Rafikayati S.Pd.,M.Pd dan Muhammad Nurrohman Jauhari S.Pd.,M.Pd pada tanggal 30 Maret 2018. Kegiatan dilaksanakan dengan menyampaikan paparan materi kemudian dilakukan tanya jawab dan diskusi dengan orang tua anak berkebutuhan khusus. Di akhir kegiatan dilakukan pengambilan kesimpulan dari paparan materi tersebut oleh pemateri dan juga oleh peserta.

\section{HASIL DAN PEMBAHASAN}

\section{A. Anak Berkebutuhan Khusus}

\section{Pengertian Anak Berkebutuhan} Khusus

Efendi (2008) menjelaskan bahwa, "Anak-anak luar biasa didefinisikan sebagai anak-anak yang berbeda dari anak-anak biasa dalam hal ciri-ciri mental, kemampuan sensorik, kemampuan komunikasi, tingkah laku sosial, ataupun ciri-ciri fisik" (hlm 36). Sedangkan Wardani, dkk (2009) mendefinisikan bahwa "Anak luar biasa adalah anak yang mempunyai sesuatu yang luar biasa yang secara signifikan membedakannya dengan anak-anak seusia pada umumnya" (hlm 1.3).

2. Klasifikasi Anak Berkebutuhan Khusus

Anak berkebutuhan khusus terdiri dari berbagai macam jenis, antara lain Tunanetra, Tunarungu, Tunagrahita, Tunadaksa dan Tunalaras. Berikut ini akan dijelaskan satu persatu mengenai masing-masing jenis anak berkebutuhan khusus di atas.

1) Tunanetra a) Pengertian Tunanetra

Barraga mengemukakan definisi tunanetra yang didasarkan pada pendidikan bahwa anak tunanetra adalah anak yang mempunyai gangguan atau kerusakan penglihatan yang berakibat pada aktivitas belajarnya. Pembelajaran yang diberikan perlu melihat karakteristik dan kelemahan dari anak, selain itu model-model maupun bahan ajarnya juga perlu disesuaikan (dalam Wardani, dkk., 2009: 4.5). Sedangkan Efendi (2006) menjelaskan bahwa seseorang yang menderita kelainan penglihatan atau tunanetra adalah mereka yang mengalami kelainan atau gangguan pada organ mata dalam proses fisiologis dimana bayangan benda yang ditangkap oleh mata tidak dapat diteruskan oleh kornea, lensa mata, retina dan ke saraf karena suatu sebab.

Berdasarkan pengertian di atas mengenai definisi tunatera, penulis menarik kesimpulan bahwa tunanetra adalah anak yang mengalami kebutuhan khusus dalam penglihatannya baik secara ringan maupun berat, dan membutuhkan pelayanan khusus terkait dengan kebutuhannya tersebut.

b) Karakteristik Tunanetra

Muhammad mengemukakan ciri-

ciri anak dengan gangguan penglihatan yaitu:

(1) Aspek fisik, meliputi: mata selalu bergerak dan bola mata berputar-putar; kurang merespon dan kurang sensitif terhadap cahaya; pupil terlihat keruh dan ada bintik-bintik putih; mata berair dan bagian tepinya berwarna merah.

(2) Aspek tingkah laku, meliputi: sering membaca maupun 
melihat sesuatu dengan jarak yang terlalu dekat; sering menabrak benda; sering mengusap, mengedipkan, memicingkan dan menutup sebelah mata

(3) Aspek keluhan, meliputi: penglihatan kabur terutama setelah melakukan pekerjaan dengan konsentrasi tinggi dan penglihatan berbayangbayang; (2008).

2) Tunarungu

a) Pengertian Tunarungu

Tunarungu secara umum dikenal masyarakat dengan orang tuli atau tidak dapat mendengar dengan baik. Secara lebih jelas akan dipaparkan mengenai pengertian tunarungu dari beberapa pendapat, antara lain adalah Pendapat dari Direktorat Pendidikan Luar Biasa ( 2004) yang menjelaskan bahwa Tunarungu adalah "anak yang kehilangan seluruh atau sebagian daya pendengarannya sehingga tidak atau kurang mampu berkomunikasi secara verbal dan walaupun telah diberikan pertolongan dengan alat bantu dengar masih tetap memerlukan pelayanan pendidikan khusus".

Pendapat selanjutnya adalah Hallahan dan Kauffman yang menyatakan bahwa tunarungu (hearing impairment) merupakan satu istilah umum yang menunjukkan ketidakmampuan mendengar dari yang ringan sampai yang berat sekali yang digolongkan kepada tuli (deaf) dan kurang dengar (a hard of hearing) (dalam Wardani, dkk.2009:5.3).

Berdasarkan pendapat di atas dapat penulis tarik kesimpulan bahwa tunarungu adalah anak yang memiliki kebutuhan khusus atau kelainan dalam pancaindranya berupa telinga yang membutuhkan pelayanan khusus sesuai dengan kebutuhannya. b) Karakteristik Tunarungu Menurut Direktorat Pendidikan Luar Biasa (2004) karakteristik siswa tunarungu adalah sebagai berikut:

(1) Secara nyata tidak mampu mendengar,

(2) Terlambat perkembangan bahasa,

(3) Sering menggunakan isyarat dalam berkomunikasi,

(4) Kurang/ tidak tanggap bila diajak berbicara,

(5) Ucapan kata tidak jelas,

(6) Kualitas suara aneh/monoton,

(7) Sering memiringkan kepala dalam usaha mendengar,

(8) Banyak perhatian terhadap getaran,

(9) Keluar cairan nanah dari kedua telinga

3) Tunagrahita

a) Pengertian Tunagrahita Anak tungarahita biasanya mendapat istilah idiot bahkan anak gila oleh beberapa masyarakat umum yang awam dengan dunia pendidikan luar biasa. Untuk lebih mengetahui pengertian anak tunagrahita, berikut ada beberapa pendapat tentang pengertian anak tunagrahita antara lain,

Sedangkan Direktorat Pendidikan Luar Biasa (2004) berpendapat tunagrahita (retardasi mental) adalah "anak yang secara nyata mengalami hambatan dan keterbelakangan perkembangan mental intelektual jauh di bawah rata-rata sedemikian rupa sehingga mengalami kesulitan dalam tugas-tugas akademik, komunikasi maupun sosial, dan karenanya memerlukan 
layanan pendidikan khusus" (hlm 16).

b) Karakteristik Tunagrahita Ada beberapa cirri/cirri atau karakteristik untuk dapat mengenali anak tungrahita antara lain adalah dengan melihat beberapa hal yang khas pada anak tungarahita. Karaketristik anak tunagrahita dijelaskan Menurut Direktorat Pendidikan Luar Biasa (2004) karakteristik siswatunagrahita adalah sebagai berikut

(1) Penampilan fisik tidak seimbang, misalnya kepala terlalu kecil/ besar,

(2) Tidak dapat mengurus diri sendiri sesuai usia,

(3) Perkembangan bicara/bahasa terlambat,

(4) Tidak ada/ kurang sekali perhatiannya terhadap lingkungan (pandangan kosong),

(5) Koordinasi gerakan kurang (gerakan sering tidak terkendali),

(6) Sering keluar ludah (cairan) dari mulut (ngiler) (hlm.19).

4) Tunadaksa

a) Pengertian Tunadaksa Efendi (2006) juga mengemukakan gambaran mengenai seseorang yang dikatakan sebagai tunadaksa yaitu sebagai berikut:

Secara etiologis gambaran seseorang yang diidentifikasikan mengalami ketunadaksaan, yaitu seseorang yang mengalami kesulitan mengoptimalkan fungsi anggota tubuh sebagai akibat dari luka, penyakit, pertumbuhan yang salah bentuk, dan akibatnya kemampuan untuk melakukan gerakan-gerakan tubuh tertentu mengalami penurunan. Secara definitif pengertian kelainan fungsi anggota tubuh (tunadaksa) adalah ketidakmampuan anggota tubuh untuk melaksanakan fungsinya disebabkan oleh berkurangnya kemampuan anggota tubuh untuk melaksanakan fungsi secara normal ... akibat luka, penyakit, atau pertumbuhan yang tidak sempurna (Suroyo, 1977) sehingga untuk kepentingan pembelajarannya perlu layanan secara khusus (hlm. 114).

Selanjunya pengertian tunadaksa menurut Wardani, dkk (2009) menyatakan bahwa, "Tunadaksa adalah penyandang bentuk kelainan atau kecacatan pada sistem otot, tulang dan persendian yang dapat mengakibatkan gangguan koordinasi, komunikasi, adaptasi, mobilitas, dan gangguan perkembangan keutuhan pribadi" (7.3).

b) Karakteristik Tunadaksa Menurut Wardani, dkk karakteristik anak tunadaksa ditinjau dari beberapa segi, antara lain:

(1) Karakteristik akademis anak tunadaksa meliputi ciri khas kecerdasan, kemampuan kognisi, persepsi dan simbolisasi mengalami kelainan karena terganggunya sistem cerebral sehingga mengalami hambatan dalam belajar, dan mengurus diri. Anak tunadaksa karena kelainan pada sistem otot dan rangka tidak terganggu sehingga 
dapat belajar seperti anak normal.

(2) Karakteristik sosial/emosional anak tunadaksa menunjukkan bahwa konsep diri dan respon serta sikap masyarakat yang negatif terhadap anak tunadaksa mengakibatkan anak tunadaksa merasa tidak mampu, tidak berguna, dan menjadi rendah diri. Akibatnya, kepercayaan dirinya hilang dan akhirnya tidak dapat menyesuaikan diri dengan lingkungan sosialnya. Mereka juga menunjukkan sikap mudah tersinggung, mudah marah, lekas putus asa, rendah diri, kurang dapat bergaul, malu dan suka menyendiri, serta frustasi berat.

(3) Karakteristik fisik/kesehatan anak tunadaksa biasanya selain mengalami cacat tubuh, juga mengalami gangguan lain, seperti sakit gigi, berkurangnya daya pendengaran, penglihatan, gangguan bicara, dan gangguan motorik (2009).

5) Tunalaras

a) Pengertian Tunalaras

Tunalaras banyak disebut dengan istilah anak nakal pada masyarakat. Tetapi pada dasrny, masyarakat awam tidak memahami dengan baik pengertian mengenai tunalaras. Seecara lebih jelaa, akan dipaparkan pengertian mengenai tunalaras agar menambah wawasan mengenai pengertian terhadap tunalaras.

Selanjutnya menurut UndangUndang Pokok Pendidikan Nomor 12 Tahun 1952, anak tunalaras adalah individu yang mempunyai tingkah laku menyimpang/berkelainan, tidak memiliki sikap, melakukan pelanggaran terhadap peraturan dan norma-norma sosial dengan frekuensi yang cukup besar, tidak/kurang mempunyai toleransi terhadap kelompok dan orang lain, serta mudah terpengaruh oleh suasana, sehingga membuat kesulitan bagi diri sendiri maupun orang lain (dalam Efendi, 2006:143).

Sedangkan Council for Children with Behaviour Disorders, suatu kelompok yang terdiri dari perwakilan beberapa organisasi profesional mendefinisikan tunalaras dengan istilah gangguan emosional/gangguan perilaku (emotional/behavioral disorder), yaitu ketidakmampuan mengendalikan emosi dan perilaku dalam program pembelajaran dan akan berdampak buruk terhadap kemampuan akademis, sosial, keterampilan, dan kepribadian (dalam Smith, 2006: 146).

b) Karakteristik Tunalaras Efendi (2006) beberapa ciri yang tampak menonjol pada kepribadian anak tunalaras adalah:

(1) Kurang percaya diri

(2) Menunjukkan sikap curiga pada orang lain

(3) Selalu dihinggapi perasaan rendah diri atau sebaliknya

(4) Selalu menunjukkan permusuhan dengan orang lain

(5) Suka mengisolasi diri

(6) Kecemasan/ketakutan yang berlebihan

(7) Tidak memiliki ketenangan jiwa

(8) Beberapa hiperaktif

(9) Sering melakukan bentrokan atau perkelahian (hlm 160)

6) Anak kesulitan belajar

Abdurrahman (2009: 8) batasan kesulitan belajar menurut The Board of The Association for Children and Adult with Learning Disabilities (ACALD) adalah sebagai berikut: "Kesulitan belajar khusus adalah suatu kondisi kronis yang diduga bersumber neurologis yang secara selektif mengganggu perkembangan, integrasi, kemampuan verbal dan/atau non verbal. Kesulitan belajar khusus tampil sebagai suatu kondisi ketidakmampuan yang nyata pada orang-orang yang memiliki sistem sensori yang cukup dan kesempatan untuk belajar yang cukup 
pula. Berbagai kondisi tersebut bervariasi dalam perwujudan dan derajatnya. Kondisi tersebut dapat berpengaruh terhadap harga diri, pendidikan, pekerjaan, sosialisasi, dan atau aktivitas kehidupan sehari-hari sepanjang kehidupan."

MenurutMunawir Yusuf, Sunardi, MulyonoAbdurrahaman $\quad(2003: 12)$ kesulitanbelajardikelompokkanmenjadid ua:

a) Kesulitanbelajarakademikterdiridari:

(1) Gangguanmotorik dan persepsi atau difraksia

(2) Kesulitan belajar kognitif meliputi kesulitan dalam fungsi persepsi, pikiran, simboloisasi, penalaran, dan pemecahan masalah.

(3) Gangguan perkembangan bahasa yang ditandai keterbatasan menggunakan symbol linguistik dalam berkomunikasi verbal.

(4) Kesulitan dalam penyesuaian perilaku sosial sehingga perilaku anak tidak dapat diterimaolehhlingkungansosial.

b) Kesulitanbelajarakademik

(1) Kesulitanbelajarmembaca (disleksia)

Menurut Bryan dan Bryan dalam Mulyono (2009) menjelaskan definisi dari kesulitan belajar membaca (disleksia) adalah suatu kesulitan dalam mempelajari komponen-komponen kata dan kalimat, mengintegrasikan komponen-komponen kata dan kalimat.

(2) Kesulitanbelajarmenulis (disgrafia)

Menurut Jordon dalam Mulyono (2009) kesulitan belajar menulis (disgrafia) menunjuka pada adanya ketidakmampuan mengingat cara membuat huruf atau simbol-simbol matematika.
(3) Kesulitanbelajarberhitung (diskalkulia)

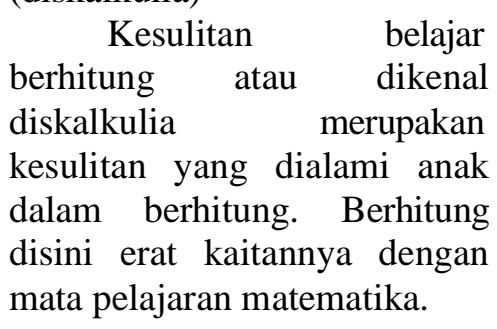

7) Autis

a) Pengertian

Menurut Handojo (2008: 12-13) Autis adalah suatu kelainan hambatan perkembangan perilaku anak yang terjadi sebelum usia 3 tahun. Autis ditandai dengan gangguan sosialisasi, komunikasi adanya perilaku autistik, dan kesulitan pengendalian emosi.

Definisi autisme berdasarkan pada Individuals withDisability Educatiob (IDEA) dalam Rahardja dan Sujarwanto (2010) menyatakanbahwa autisme adalah kelainan perkembangan yang secara signifikan berpengaruh terhadap komunikasi verbal dan non verbal serta interaksi sosial, umumnya terjadi pada usia sebelum usia tiga tahun, yang memiliki pengaruh jelek terhadap kinerja pendidikan anak. Karakteristik lain yang sering menyertai autisme seperti melakukan kegiatan yang berulang-ulang dan gerakan stereotip, penolakan terhadap perubahan lingkungan atau perubahan dalam rutinitas sehari-hari dan memberikan respon yang tidak semestinya terhadap pengalaman sensori.

b) Karakteristik

Fauziyah (2008) memaparkan karakteristik atau ciri-ciri anak autis dalam beberapa aspek perkembangannya antara lain:

(1) Komunikasi

(a) Perkembangan bahasa lambat atau sama sekali tidak ada

(b) Anak tampak seperti tuli, sulit bicara atau pernah bicara

(c) Kadang kata-kata yang digunakan tidak sesuai artinya 
(2) Interaksi sosial

(a) Penyandang autis lebih suka menyendiri

(b) Tidak ada atau sedikit kontak mata, menghindar untuk bertatapan

(c) Tidak tertarik untuk bermain bersama teman

(3) Gangguan sensoris

(a) Sangat sensitif terhadap sentuhan, seperti tidak suka dipeluk

(b) Bila mendengar suara keras langsung menutup telinga

(c) Senang mencium-cium, menjilat mainan atau benda-benda

(4) Pola bermain

(a) Tidak bermain seperti teman-teman pada umumnya

(b) Tidak suka bermain dengan teman-teman sebayanya

(c) Tidak kreatif, tidak imajinatif

(5) Perilaku

(a) Dapat berperilaku berlebihan (hiperaktif) atau kekuarangan (hipoaktif)

(b) Memperlihatkan perilaku stimulasi diri seperti bergoyang-goyang, mengepakan tangan seperti burung, berputar, dll

(c) Tidak suka pada perubahan

(6) Emosi

(a) Sering marah-marah tanpa alasan yang jelas, tertawatawa, menangis tanpa alasan

(b) Temper tantrum (mengamuk tak terkendali) jika dilarang atau tidak diberi keinginannya

(c) Kadang suka menyerang dan merusak

\section{B. KeterlibatanOrangtuadalamPenanga nanAnakBerkebutuhanKhusus}

Menurut tata bahasa, orang tua adalah ayah, ibu kandung, orang yang dianggap tua, atau orang yang dihormati atau disegani. Markum dalam Ritzer (2008)

,Lingkungan yang pertama dikenal oleh individu (anak) adalah orang tua yang terdiri dari ayah dan ibu. Maka dengan sendirinya ayah dan ibu sangat menentukan pertumbuhan dan perkembangan kepribadian seseorang anak.

Gerungan dalam Rohidi (1994)Orang tua merupakan kelompok sosial yang pertama dalam kehidupan manusia, tempat ia belajar dan menyatakan diri sebagai makhluk sosial di dalam hubungan interaksinya dengan kelompoknya. Sementara Soekanto (2006) menyatakan bahwa orang tua adalah lembaga kesatuan sosial terkecil yang secara kodrati berkewajiban mendidik anaknya. Orang tua mendidik anak secara tradisional dan turun temurun. Selain itu Kartono dalam Ritzer (2008) menyatakan bahwa orang tua merupakan unit sosial terkecil yang memberikan fondasi primer bagi perkembangan anak.

Dalam keluarga orang tua sangat berperan sebab dalam kehidupan anak waktunya sebagian besar dihabiskan dalam lingkungan keluarga apalagi anak masih di bawah pengasuhan atau anak usia sekolah dasar yaitu antara usia (0-12 tahun), terutama peran seorang ibu. Orang tualah yang bertugas mendidik. Dalam hal ini (secara umum) baik potensi psikomotor, kognitif maupun potensi afektif, disamping itu orang tua juga harus memelihara jasmaniah mulai dari memberi makan dan penghidupan yang layak.

Kretschmer (1978),Ling (1990) dan Ross (1990) dalam Estabrooks (1994 : 20) menambahkanbahwa khususnyaanak tunarungu lebih mudah belajar bahasa jika dalam aktivitas yang dekat dengan orang tua dan pengasuh. Merupakan tugas orang tua untuk memberikan kekayaan interaksi bahasa lisan pada anak karena orang tua berada di samping anak dari bangun tidur sampai tidur kembali. Sebagai pemain kunci, mereka perlu 
mengembangkan pemahaman berbagai tahapan meliputi tahapan mendengarkan, berbicara, bahasa, dan kognisi. Jadi keberhasilan anak tergantung peran serta orang tua agar aktif dalam menangani anak.

Sunardi dan Sunaryo (2007:48) menyatakan bahwa orang tua adalah lingkungan terdekat dengan anak, paling mengetahui kebutuhan khususnya, paling berpengaruh, dan paling bertanggung jawab terhadap anaknya, sedangkan fungsi tenaga ahli lebih sebagai konsultan atau salah satu "social support" bagi keberhasilan anaknya.Bronfrenbrenner dalam Sunardi dan Sunaryo (2007 : 18)menambahkanbahwa keluarga merupakan altar pertama bagi anak. Kalau anak mendapatkan start yang baik dalam keluarga, maka akan dapat dengan mudah masuk dalam kehidupan berikutnya yang lebih luas. Keluarga adalah "critical system" tempat anak belajar bagaimana memuaskan kehidupanya dan bagaimana menghadapi dunia.

Setiap anak mulai belajar melalui lingkungan terdekatnya, terutama melalui kontak dengan ibunya. Selanjutnya melalui kontak dengan ayahnya serta anggota keluarga lainya, dan baru kemudian secara bertahap belajar melalui lingkungan yang lebih luas. Jika keluarga sebagai start awal sebagai tempat pertama belajar anak sudah tidak mendukung, dikhawatirkan pada tahap berikutnya yang lebih luas anak akan mengalami hambatan. Dan hal tersebut dapat berdampak pada terhambatnya perkembangan anak baik potensi maupun psikologis anak.

Hal ini ditegaskan oleh Sunardi dan Sunaryo (2007 : 22) yang menyatakan bahwa Orang tua yang kurang menjalankan fungsi, peran dan tanggung jawabnya sebagai peletak dasar bagi perkembangan optimal anak, yang juga seing berdampak pada krisis psikologis dan sosial yang berlarut-larut yang pada akhirnya bermuara pada terhambatnya respon positif dan konstruksi terhadap kekurangan yang dialami anak.

\section{KESIMPULAN}

Untuk mensukseskan intervensi dini dan mengingat usia anak yang masih kecil, tentu peran orang tua adalah yang terpenting. Hal ini dikarenakan orangtua adalah orang terdekat anak dan orang yang selalu bersama anak. Keterlibatan orangtua adalah sangat penting untuk mewujudkan pembelajaran yang optimal. Adalah peran orangtua untuk mengembangkan potensi psikomotor, kognitif maupun potensi afektif, disamping itu orangtua juga harus memelihara jasmaniah mulai dari memberi makan dan penghidupan yang layak.

\section{REFERENSI}

Brereton,Avril V. 2009. Autism Spectrum Disorders Parent education and skillss training: a practical and effective way to help.Monash University: ACT-NOW Fact Sheet 50.

Brown, MB. 2000. Recommended Practices: Parent Education and Support. (Online), (http://ag.udel.edu/extension/fam/b est/crp-part100.htmldiakses $\quad 16$ Desember 2017).

Estabrooks. W. 1994. Auditory Verbal Therapy for Parents And Professionals. Washington DC, U.S.A. :Alexander Graham Bell Association for the deaf.

Feher, Terri. 1996. Stress and Coping in Families with Deaf Children. Journal of Deaf Studies and Deaf Education Vol 1 (3): 155-166.

Feldman \& Werner.2002.The Development of A Family Life Education Manual for Teaching Parenting Skillss to Incarcerated Fathers.Dissertation. Miami University.

Gargiulo, Richard M. 2012. Speial Education in Contemporary Society: An Introduction to Exceptionality $4^{\text {th }}$ ed. California: Sage Publication.Inc.

Hasan, M. 2011. Pendidikan Anak Usia Dini. Diva Press: Yogyakarta.

Hotchkiss, Jacqueline Suzanne., Biddle, Kimberly dan Sacramento. 2009. Implementing parenting education policy to overcome parental stress and foster educational and 
behavioral competence in children. California: California State University.

Munfaati, Hanum.2014.Pengaruh Pola Asuh Orang Tua Terhadap Kemampuan Kognitif Anak Tunarungu di TKLBB Dharma Wanita Sidoarjo. Surabaya: Jurnal Publikasi Program studi Pendidikan Luar Biasa UNESA

Nada (2000) Dampak Pola Asuh Orang Tua Terhadap Disiplin Anak Kelompok A RA. Tarbiyatul Akhlaq Krembangan, Taman. Surabaya: Skripsi tidak dipublikasikan. UNESA.

Slemenda, Jack. 2008. Auditory Verbal Therapy. (Online), (http://www.deafed.net, diakses 15 Desember 2017).

Somantri, S. 2006. Psikologi Anak Luar Biasa. PT. Refika Aditama: Bandung.

Sunardi dan Sunaryo. 2007. Intervensi Dini Anak Berkebutuhan Khusus. Jakarta : Depdiknas.
Thomas J. Berndt (1997) Parental Socialization of Positive and Negative Emotions: Associations With Children's Everyday Coping and Display Rule Knowledge.

Dissertation. North Carolina University.

Thomas, R. \& Zimmer-Gembeck, M. (2007). Behavioral outcomes of parentchild interaction therapy and Triple $P_{i}$ Positive Parenting Program: A review and meta-analysis. Journal ofAbnormal Child Psychology, 35, pp. $475-495$

Van Ryzin, Mark J dkk. 2016. Family-Based Prevention Programs for Children and Adolescents. New York: Psychology press.

Zepeda, Marlene dkk. 2004. Improving Children's Behaviour and Attendance throughthe Use of Parenting Programmes:An Examination of Good Practice.London: Institute of Education, University of London. 